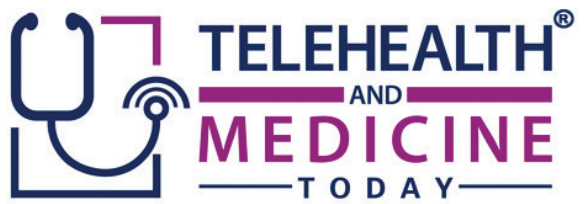

SPECIAL ISSUE EDITORIAL

\title{
Proceedings of the 16 th International Conference of Telemedicine Society of India
}

\author{
Krishnan Ganapathy*, M.Ch (NEURO) FACS FICS FAMS Ph.D \\ Director, Apollo Telemedicine Networking Foundation, Chennai, India
}

I $\mathrm{t}$ is a sign of the times that Telehealth and Medicine Today, a US based journal, is bringing out a Special Issue to highlight proceedings of the 16th International Annual Conference of the 'Telemedicine Society of India' (TSI) (http://www.telemedicon.in/), which was held virtually from 18 to 20 December, 2020. For two decades, we have been relentlessly knocking at doors, pleading to be heard and crying hoarse that Telehealth alone can bridge the ever-increasing gap in the healthcare sector. A strand of RNA has become the Global Chief Transformation Officer (CTO), radically transforming virtual health care and ensuring that soon we will be centre stage. It has been my privilege to have been part of this exciting journey for the last two decades. The Tamil Nadu chapter of TSI under the leadership of Prof. Sunil Shroff, Organising Secretary, along with four other TSI state chapters Delhi-National Capital Region (NCR), Rajasthan, Maharashtra and Karnataka, organised this conference within 8 weeks (Fig. 1). The theme of the conference was to demonstrate that Telemedicine in India had moved from 'Fringes to the Mainstream'.

With 850 members pan India, TSI is, indeed, unique in its multi-disciplinary membership. Clinicians, engineers, technologists, Information and Communication
Technology (ICT) specialists, hospital administrators, in fact, all stakeholders of the healthcare ecosystem are represented. Of the 1,126 virtual attendees, 586 were doctors and 154 were students. The industry was represented with 12 stalls in a Virtual Exhibition stall.

In order to accommodate the wide-ranging scientific programme, three sessions were held concurrently for 3 days. There were $52 \mathrm{~h}$ of deliberations on Telehealth, which included 18 Continuing Medical Education(CME's), symposia and workshops, including a hackathon. The entire proceedings have been made available at www.telemedicon.in. The Maharashtra Medical Council has recognized the event as a Continuing Medical Education CME activity for four credit hours. The 34 free papers included 14 ePosters. Prizes were awarded for the best papers. Invited speakers included a Judge of the Supreme Court of India, Member Health of the Niti Aayog (erstwhile Planning Commission of India), Secretary-level officers of the Govt of India, Chief Scientist WHO, Secretary International Society for Telemedicine and eHealth (ISfTeH) and seven renowned exponents of Telehealth from the United States and United Kingdom. A booklet 'Telemedicine Practice Guidelines FAQ's for Medical Practitioners from TSI' was released. TELEMEDCION2020 was attended by at least

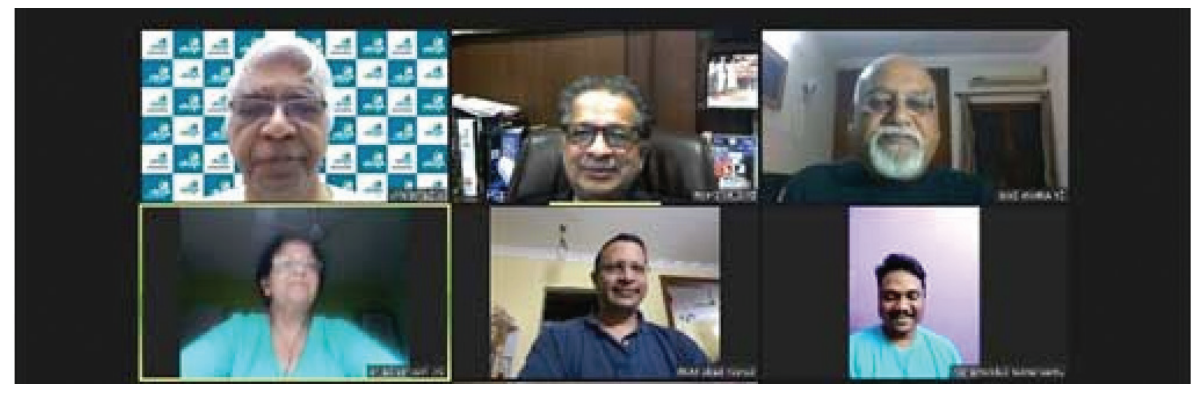

Fig. 1. Scientific Committee in a virtual meeting.

*Correspondence: Krishnan Ganapathy. Email: drganapathy@apollohospitals.com 


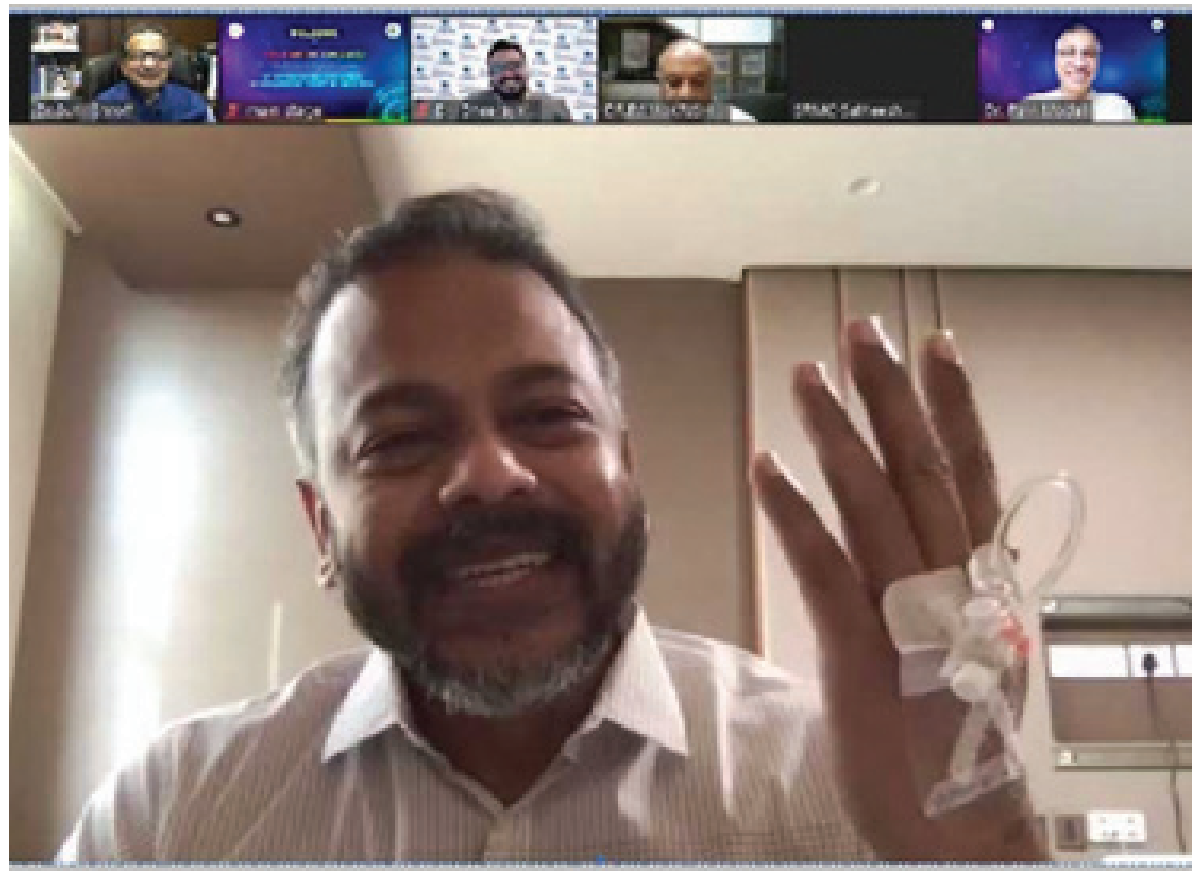

Fig. 2. Hospital CEO afflicted with COVID-19 addressing the conference from the hospital bed.

four speakers suffering from active coronavirus disease 2019 (COVID-19 infections. Several attendees were just recovering or had recovered. One of them spoke from his hospital bed (Fig. 2).

Abstracts of many topics covered in guest lectures, keynote addresses, symposia, workshops, inaugural address and valedictory address have been included.

The full text of nine papers presented at the conference along with $\mathbf{5 6}$ abstracts has been published. We have no doubt that through TSI's (www.tsi.org.in) first forced virtual conference, we have reached the critical mass essential for a successful take-off. Using Telehealth is no longer a question of 'if', it is not even 'how', it is a question of 'Now'. The enthusiasm showed by the attendees, organisers, supporters and knowledge partners had to be seen to be believed. Most importantly, participation of very senior government officers in the conference has sent a clear message that Telehealth in India has come to stay. No doubt, COVID-19 accelerated the entire process, and virtual remote health care is now being accepted by all stakeholders in the Indian healthcare ecosystem. On behalf of the Telemedicine Society of India, we would like to once again place on record our gratitude to the editors of Telehealth and Medicine Today for making this Special Issue happen. We look forward to further strengthening the close bond that have already been created by members of the Telehealth community in India and the United States. 